\title{
Graft outflow vein unification venoplasty with superficial left hepatic vein branch in pediatric living donor liver transplantation using a left lateral section graft
}

\author{
Jung-Man Namgoong, Shin Hwang, Gil-Chun Park, \\ Hyunhee Kwon, Yong Jae Kwon, and Sang Hoon Kim
}

\author{
Department of Surgery, Asan Medical Center, University of Ulsan College of Medicine, Seoul, Korea
}

\begin{abstract}
Orifice size of the left hepatic vein trunk (LHV) in left lateral segment (LLS) grafts is often too small to perform direct anastomosis. A small superficial branch of LHV is encountered in approximately $30 \%$ of LLS grafts. Unification venoplasty of the LHV trunk and its superficial vein branch makes the orifice size of LLS outflow vein larger than the original size. We present refined surgical techniques for LHV unification venoplasty with a superficial LHV branch. The patient was a 5-month-old $9 \mathrm{~kg}$-weighing girl with biliary atresia. Her general condition deteriorated, but there was low possibility of deceased donor liver allocation, thus living donor liver transplantation was performed using her mother's LLS. The graft hepatic vein was widened through unification venoplasty of LHV and its superficial branch. Recipient hepatic vein orifice was widened through unification of three hepatic veins. The graft and recipient hepatic vein orifices were well matched in size, and they were anastomosed with 5-0 continuous sutures. The portal vein was reconstructed with interposition of cold-preserved external iliac vein homograft. The graft left hepatic artery was reconstructed using the recipient right hepatic artery and hepaticojejunostomy was performed. This patient recovered uneventfully and is doing well for 3 months to date. The unification venoplasty with LHV trunk and its superficial vein branch makes the size of LLS outflow vein definitely larger than the original size, thus it can be a useful technical option to reduce the risk of hepatic vein outflow obstruction in pediatric liver transplantation using a LLS graft. (Ann Hepatobiliary Pancreat Surg 2020;24:326-332)
\end{abstract}

Key Words: Left hepatic vein; Unification venoplasty; Stenosis; Pediatric transplantation; Infant

\section{INTRODUCTION}

Generally speaking, the usual left lateral section (LLS) graft has one left hepatic vein (LHV) trunk with complete preservation of the middle hepatic vein trunk at the donor side. In this sense, the orifice size of this LHV trunk is often as small as the diameter of the retrohepatic inferior vena cava (IVC) of an infant recipient, thus this graft outflow vein orifice is often considered to be too small to perform direct anastomosis even in an infant recipient. Because some anastomotic stenosis develops at the site of LHV reconstruction in pediatric living donor liver transplantation (LDLT), ${ }^{1}$ it is important to make the graft and recipient hepatic vein orifices large enough to compensate such surgical procedure-related stenosis. Typically, a small superficial branch of the LHV is encountered in approximately $30 \%$ of the LLS or left liver grafts in our experience of 500 cases. $^{2}$ Unification venoplasty of the LHV trunk and its superficial vein branch makes the orifice size of LLS outflow vein much larger than the original size, which is beneficial to reduce the risk of hepatic vein outflow obstruction. We herein present a case and describe the refined surgical techniques for LHV unification venoplasty with a superficial LHV branch.

\section{CASE}

In this case, the infant patient was a 5-month-old girl with $65 \mathrm{~cm}$ in height and $9 \mathrm{~kg}$ in weight who suffered from biliary atresia. This patient underwent a Kasai por-

Received: April 29, 2020; Revised: April 30, 2020; Accepted: May 30, 2020

Corresponding author: Shin Hwang

Department of Surgery, Asan Medical Center, University of Ulsan College of Medicine, 88 Olympic-ro 43-gil, Songpa-gu, Seoul 05505, Korea Tel: +82-2-3010-3930, Fax: +82-2-3010-6701, E-mail: shwang@amc.seoul.kr

Copyright (C) 2020 by The Korean Association of Hepato-Biliary-Pancreatic Surgery

This is an Open Access article distributed under the terms of the Creative Commons Attribution Non-Commercial License (http://creativecommons.org/ censes/by-nc/4.0) which permits unrestricted non-commercial use, distribution, and reproduction in any medium, provided the original work is properly cited. Annals of Hepato-Biliary-Pancreatic Surgery • pISSN: 2508-5778 - elSSN: 2508-5859 
toenterostomy at 1 month after birth and had experienced a redo of the Kasai operation 20 days later. However, the patient had episodes of jaundice which progressed continuously, with laboratory findings of aspartate transaminase $600 \mathrm{IU} / \mathrm{L}$, alanine transaminase $467 \mathrm{IU} / \mathrm{L}$, alkaline phosphatase $932 \mathrm{IU} / \mathrm{L}$, albumin $2.1 \mathrm{~g} / \mathrm{dL}$, creatinine $0.17 \mathrm{mg} / \mathrm{dL}$, prothrombin INR 1.51, and total and direct bilirubin $19.1 \mathrm{mg} / \mathrm{dL}$ and $16.0 \mathrm{mg} / \mathrm{dL}$, respectively. Because that the pediatric end-stage liver disease score (PELD) of this patient was 21, there was a low possibility of organ allocation for split or whole liver transplantation. In what follows, the general condition of this patient de- teriorated progressively, thus we decided to perform a LDLT operation at the age of 5 months. In this scheme, the donor was the 38 -year-old mother of this patient.

To begin with, a 250 g-weighing LLS graft was harvested through a laparotomy with an upper midline incision. The transverse diameter of the graft LHV orifice was $15 \mathrm{~mm}$ and a $3 \mathrm{~mm}$-sized superficial branch of the LHV was attached (Fig. 1A). This superficial LHV branch was incised by $10 \mathrm{~mm}$ in length to expose the vein lumen (Fig. 1B, C). Next, the septum between the LHV trunk and its superficial branch was incised and some intervening hepatic parenchyma was excised (Fig. 1D-F). Thereaf-
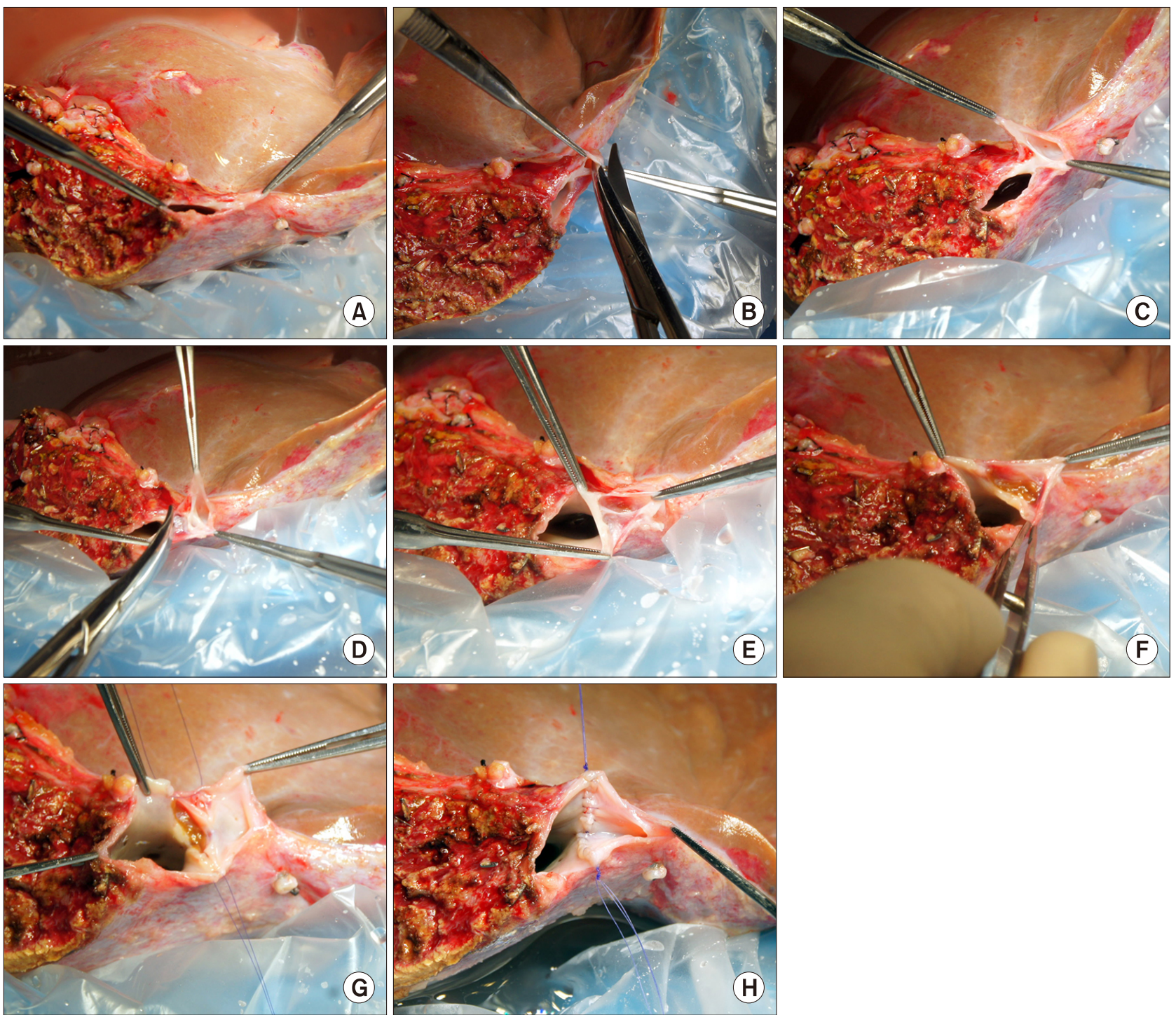

Fig. 1. Intraoperative photographs of bench work. (A) A small superficial branch of the left hepatic vein is located at the left end of the left hepatic vein stump. (B and C) This vein branch was incised to expose the lumen. (D-F) A septum between the two vein orifices was incised and some intervening hepatic parenchyma was excised. $(\mathrm{G}$ and $\mathrm{H})$ The two graft vein openings were unified with the use of continuous sutures using a 6-0 PDS. 
ter, these two vein openings were unified with continuous sutures using a 6-0 PDS (Fig. 1G, H). This unification procedure made the transverse diameter of the graft vein orifice as large as $25 \mathrm{~mm}$.

After dissection of the recipient native liver was completed (Fig. 2A), the hepatic parenchyma was incised by a surgical knife, by which a bulk of hepatic parenchyma was left around the hepatic vein trunks (Fig. 2B, C). Next, a longitudinal incision was applied at the hepatic parenchyma between the right and middle hepatic vein trunks, and then the attached hepatic parenchyma was separated into two parts (Fig. 2D). Thereafter, the hepatic parenchyma was forcefully pulled out to detach from the hepatic vein stumps, which made the hepatic vein stump walls long and thick (Fig. 2E). At that time, the IVC wall septa between the right and middle hepatic veins and the middle and left hepatic veins were incised consecutively to make a single large hepatic vein orifice (Fig. 2F). The anterior wall defect between the right and middle hepatic vein stumps at this hepatic vein orifice was repaired with
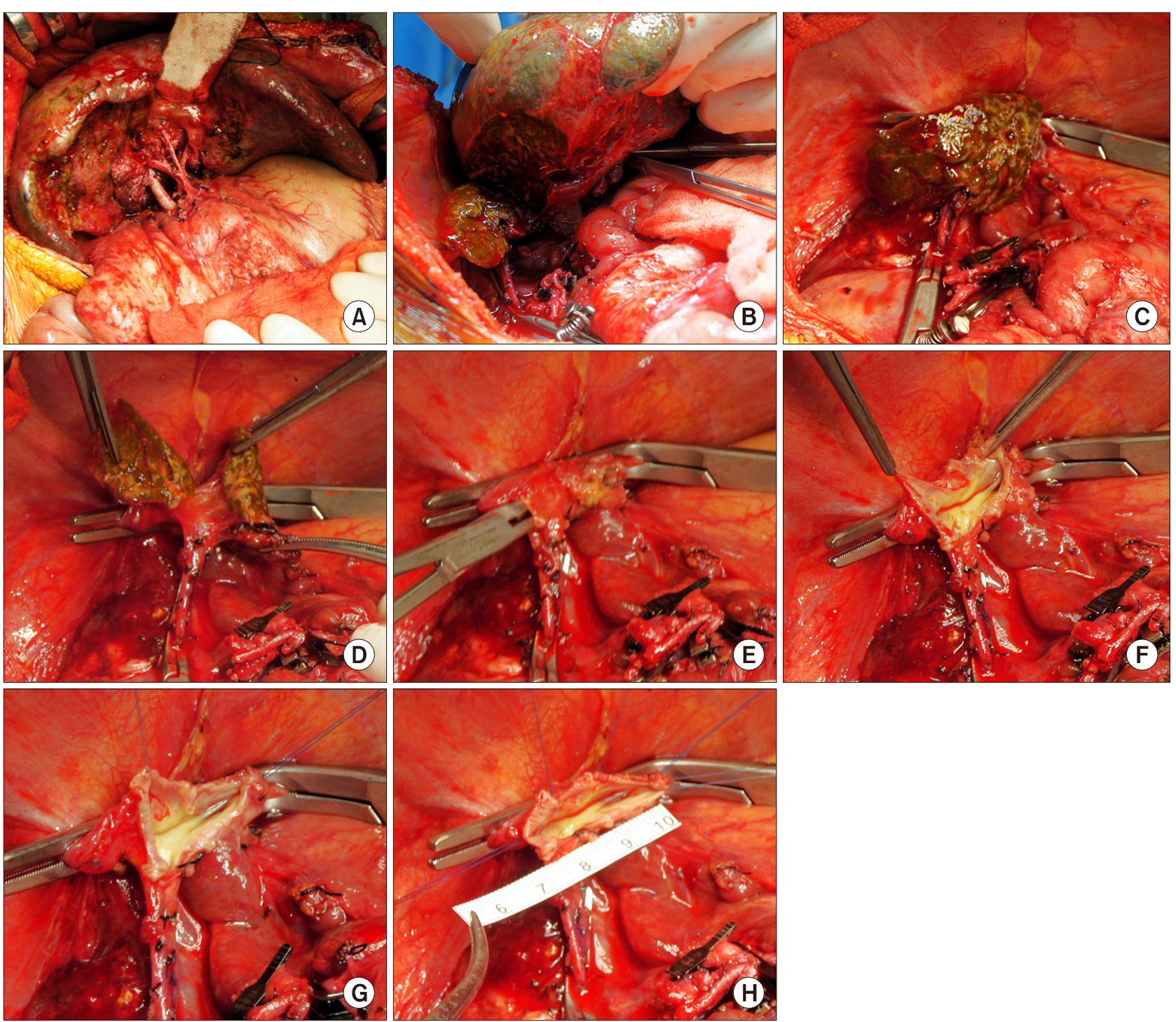

Fig. 2. Intraoperative photographs of recipient hepatic vein preparation. (A) The native liver of the recipient was completely dissected. (B) The hepatic parenchyma was incised with a surgical knife. (C) A bulk of the hepatic parenchyma was left around the hepatic veins. (D) A longitudinal incision was applied at the hepatic parenchyma between the right and middle hepatic vein trunks, by which the attached parenchyma was separated. (E and F) The hepatic parenchyma was forcefully pulled out to detach from the hepatic vein stumps, and the septa between the right and middle hepatic veins and the middle and left hepatic veins were incised. $(\mathrm{G}$ and $\mathrm{H}$ ) The defect at the anterior wall between the right and middle hepatic vein stumps was repaired with continuous sutures using a 6-0 PDS. 
continuous sutures using a 6-0 PDS (Fig. 2G). At that time, this unification procedure made the transverse diameter of hepatic vein orifice as large as $30 \mathrm{~mm}$, although the diameter of the retrohepatic IVC was noted as being close to $15 \mathrm{~mm}$ (Fig. 2H).

Because the portal vein was hypoplastic according to the disease nature of biliary atresia, a vein interposition technique was applied using a cold-stored external iliac vein homograft (Fig. 3), which was presented previously. ${ }^{3}$ Next after spreading slush ice, the LLS graft implantation was initiated. The right and left corners of the graft and recipient hepatic vein orifices were tagged with a 5-0 PDS to match their sizes (Fig. 4A). Then, continuous sutures of the posterior wall continued first from the left corner to the 6 o'clock direction (Fig. 4B, C), and then the suturing continued toward the right corner after meticulous size patching (Fig. 4D). An additional longitudinal incision at the anterior wall of the IVC was not necessary, because the size matching at this portion was considered to be of an adequate nature. After placing a fixation suture at the right corner, the suturing continued to the anastomose of the anterior wall (Fig. 4E, F). After injecting heparinized saline into the IVC lumen, the graft hepatic vein reconstruction was completed.

Thereafter, the interposed recipient portal vein conduit was stretched toward the graft portal vein, and some redundant portion was excised after length matching. A portal vein reconstruction was performed with continuous sutures using a 6-0 PDS (Fig. 5). Just after that, the graft reperfusion was continued. The graft left hepatic artery was reconstructed using the recipient right hepatic artery branch under the use of a surgical microscopy (Fig. 6A). An hepaticojejunostomy was performed using the preformed Roux-en-Y jejunal limb (Fig. 6B).

This patient recovered uneventfully without any surgical complication (Fig. 7), and is doing well for 3 months to date.

\section{DISCUSSION}

Pediatric LDLT in infant recipients is vulnerable to various vascular complications, because the graft and recipi-
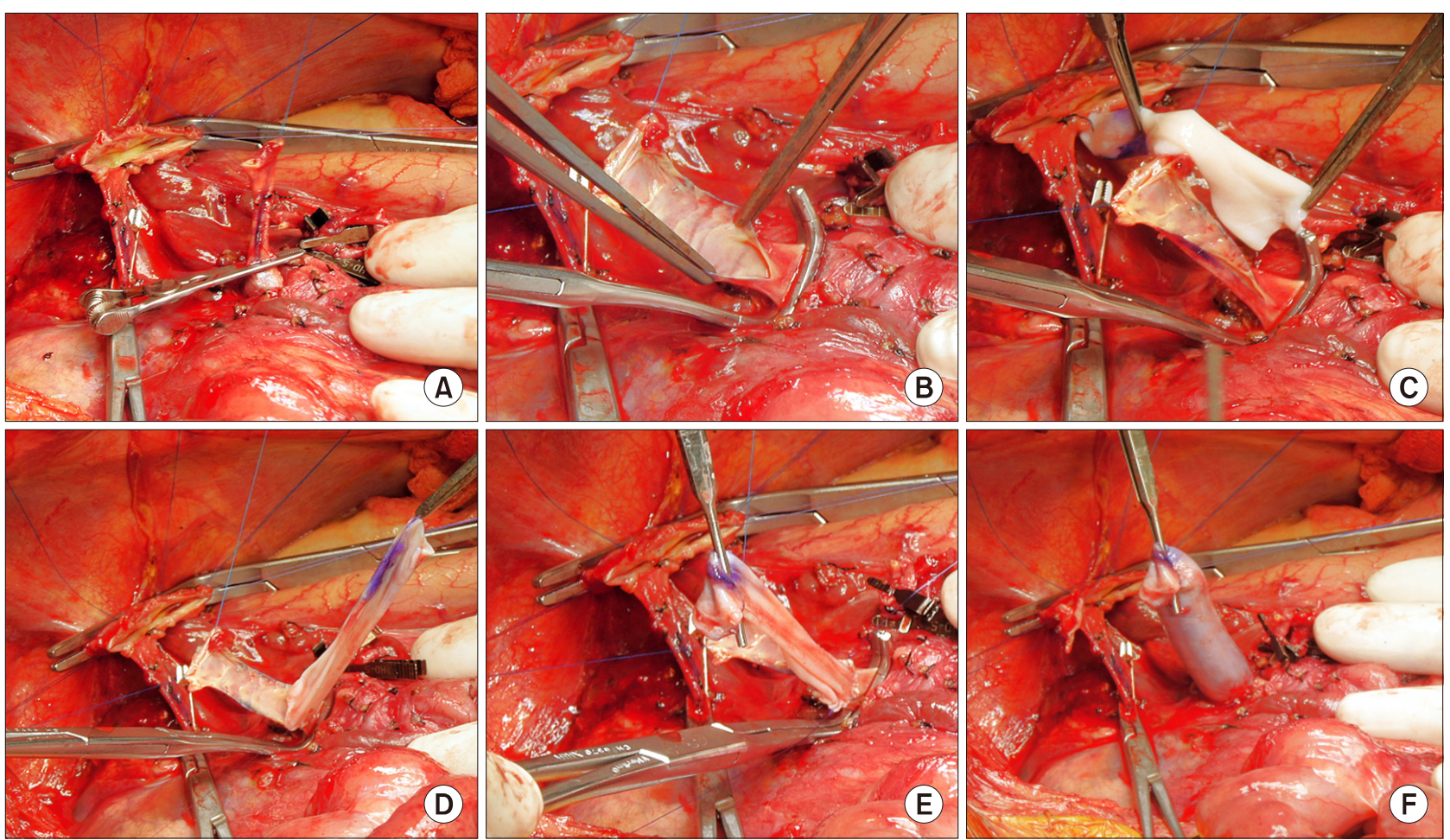

Fig. 3. Intraoperative photographs of recipient portal vein interposition with a cold-preserved external iliac vein homograft. (A) The recipient portal vein was dissected extensively to the porto-splenic vein junction. (B) The anterior wall of the portal vein was incised with deeply located clamping. (C-E) A vein homograft was anastomosed to the portal vein stump through a modified end-to-end method. (F) The interposed vein conduit was distended. 

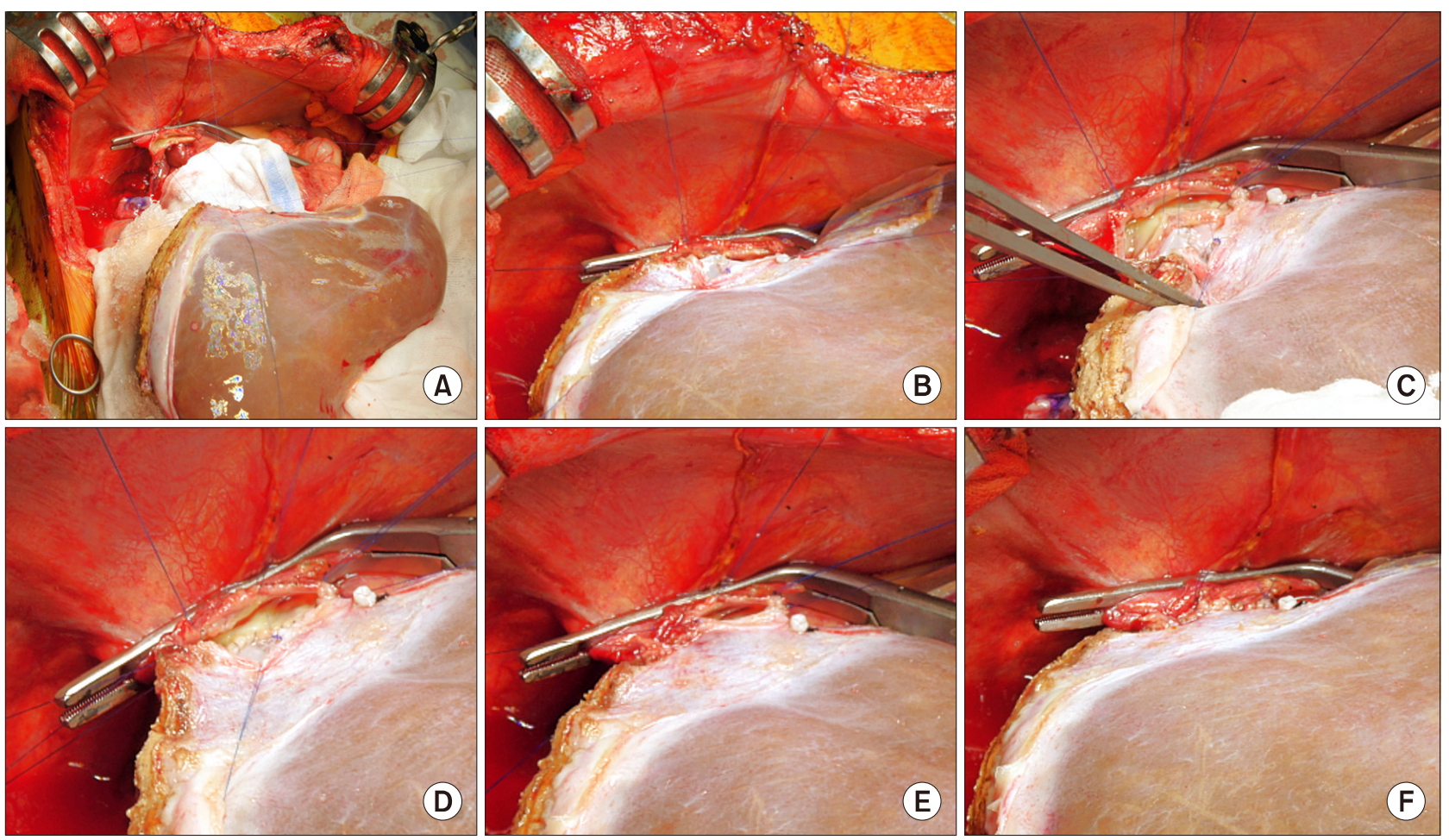

Fig. 4. Intraoperative photographs of graft hepatic vein reconstruction. (A) The right and left corners of the graft and recipient hepatic vein orifices were tagged with a 5-0 PDS. (B and C) Continuous sutures of the posterior wall continued from the left corner to the 6 o'clock direction. (D) Suturing continued toward the right corner after meticulous size patching. (E and F) Suturing continued to anastomose the anterior wall.
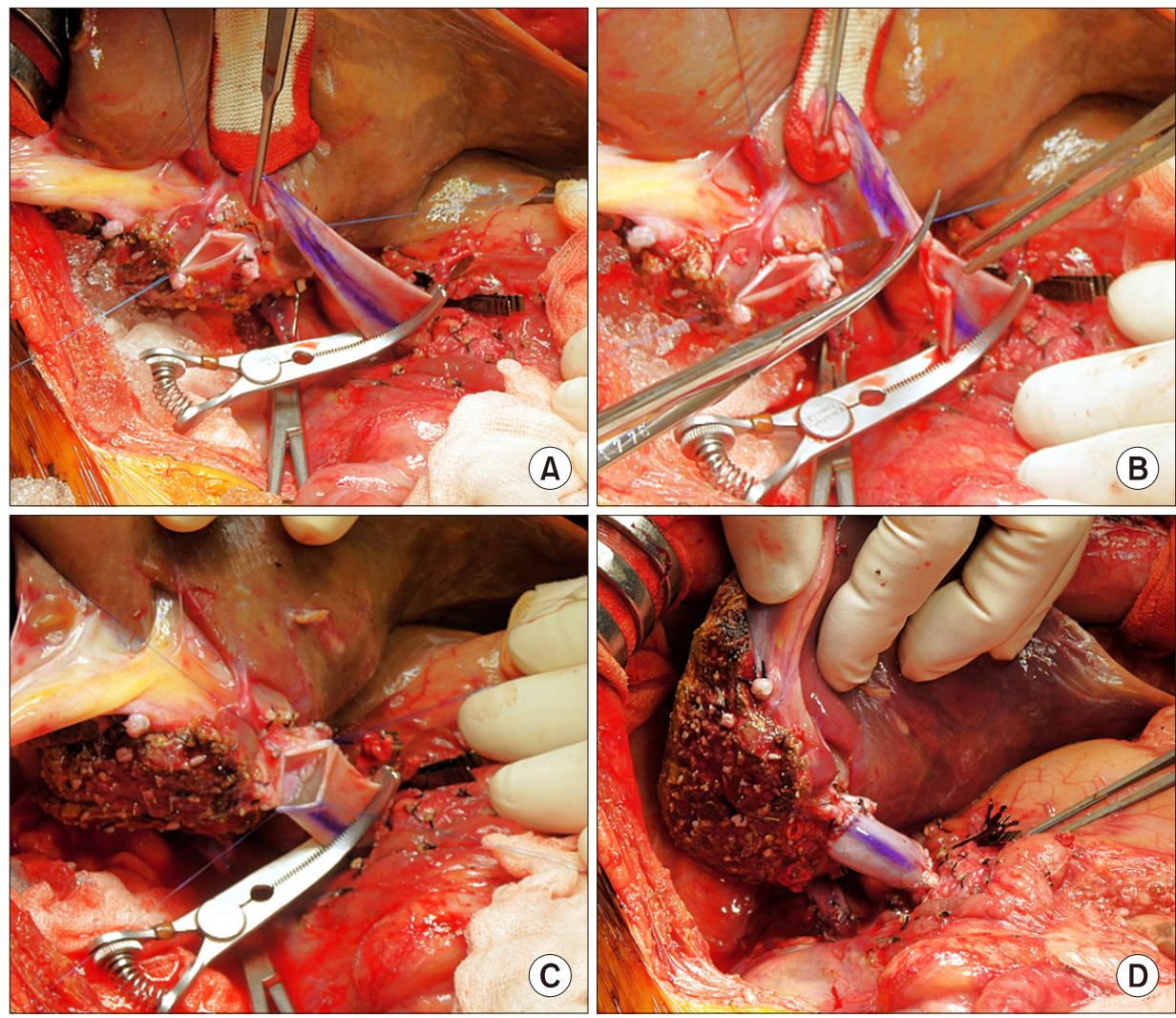

Fig. 5. Intraoperative photographs of graft portal vein reconstruction. (A and B) The interposed vein conduit was stretched toward the graft portal vein and the redundant portion was excised. (C) Portal vein anastomosis was performed with continuous sutures using a 6-0 PDS. (D) The reconstructed portal vein was distended after a graft reperfusion. The marked line at the conduit indicates the axial direction of 12 o'clock. 


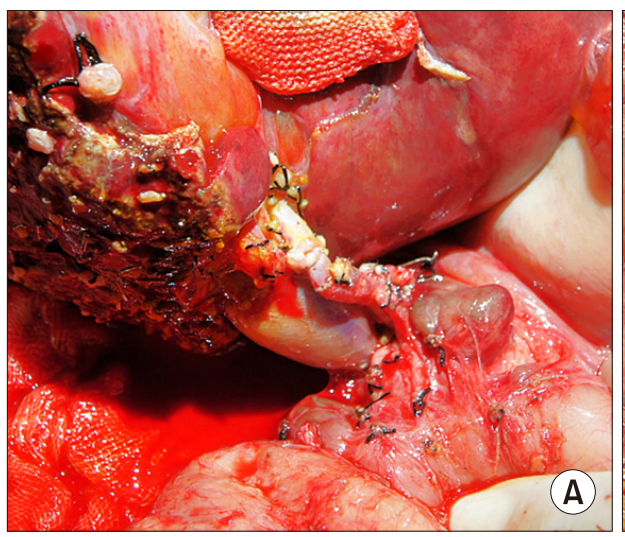

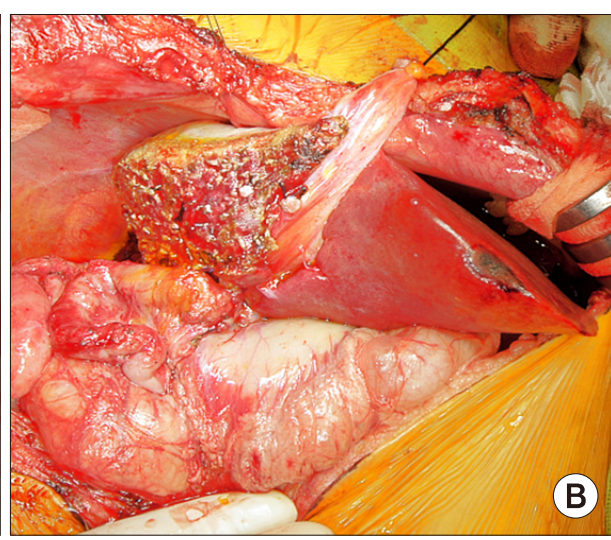

(B)
Fig. 6. Intraoperative photographs of reconstruction for graft hepatic artery and bile duct. (A) The graft left hepatic artery was reconstructed using the recipient right hepatic artery under surgical microscopy. (B) Hepaticojejunostomy was performed using the preformed Roux-en-Y jejunal limb.
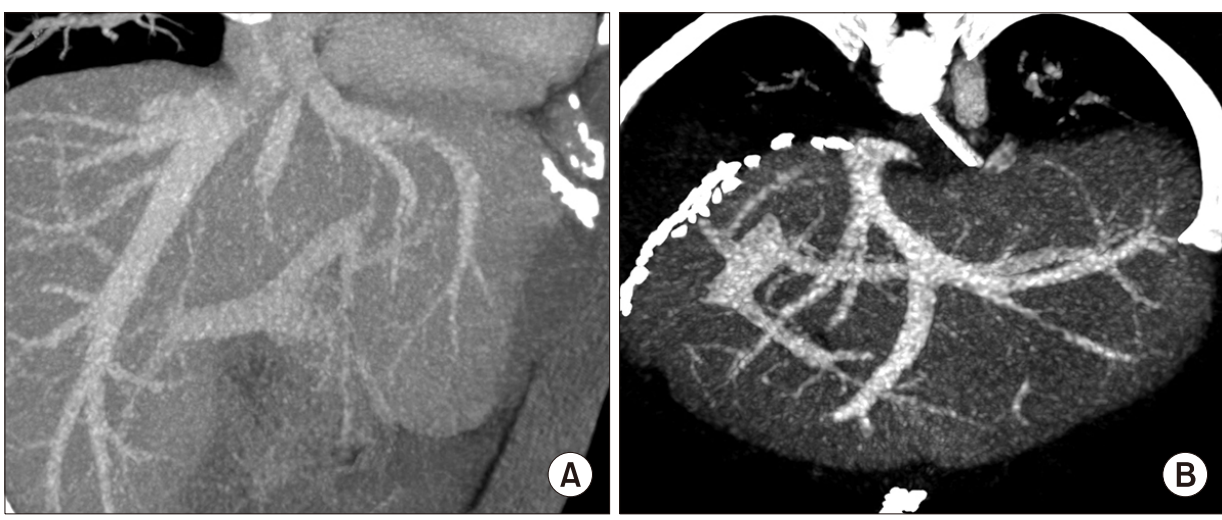

Fig. 7. Comparison of liver computed tomography (CT) scans before and after living donor liver transplantation. (A) Preoperative CT scan image shows the hepatic vein structures of the donor liver. (B) Recipient CT scan taken 5 days after transplantation shows the hepatic vein structures of the implanted left lateral section graft. ent vessels are small and the use of an endovascular stenting procedure cannot be a definitive treatment in those cases. Regarding hepatic vein reconstruction in LLS grafts, anastomotic stenosis is usually attributed to the small size of the anastomosis per se, and can be indicative of the inflammatory process around the native hepatic vascular tissues. Once an anastomotic stenosis of the graft hepatic vein develops, it is not easily treated through the use of a percutaneous radiological angioplasty, because the connective tissues around the vascular structures are hardened through the prolonged inflammatory process whereby repetitive interventional procedures are often needed. ${ }^{4-7}$ Note that the insertion of a wall stent into the hepatic vein anastomosis is regarded as a life-saving procedure to cope with hepatic vein outflow obstruction with an anticipation of late retransplantation, because such use of a vascular wall stent may not be expanded enough to follow the long-term physical growth timeframe characteristic of a patient from the years of an infant to a forming adolescent. $^{8}$ Therefore, it is critical that an evidence-based secure surgical design is essential for hepatic vein reconstruction in pediatric LDLT.
The surgical techniques for implantation of the left liver and LLS grafts are similar, but there is a definite difference in the size of the graft outflow hepatic veins. For this reason, the LLS grafts are usually used for infant recipients, thus the area of the middle hepatic vein trunk is completely preserved at the donor side in order to make the LLS graft as small as possible. In a review of the normal anatomy of the liver, a LLS graft composed of the segment II and III is shown to share a single LHV trunk. By contrast, in some variant liver anatomy, an aberrant segment III vein can drain into the middle hepatic vein trunk directly, which requires a customized design for the use of interposition procedure of graft hepatic vein reconstruction. ${ }^{3,9}$ Notably, the size of single LHV trunk in LLS grafts is usually small because only small-sized LLS grafts are intentionally selected for use with infant recipients. In those cases, such a small graft hepatic vein orifice is closely associated with the development of an anastomotic stenosis, thus it is important to make the graft hepatic vein orifices large enough to match with the recipient IVC orifice.

To enlarge the hepatic vein orifice of a LLS graft, we 
have used an incision-and-patch venoplasty technique for a long time, in which the rightl LHV wall was incised and a homograft vein patch was attached to cover the defect. Additionally, it is important to note that if a small superficial branch of LHV is present, it was incised and then a vein patch would be applied to facilitate anastomosis. These incision-and-patch venoplasty techniques are based on the concept of long-and-wide hepatic vein anastomosis, which was proposed by Imamura et al. ${ }^{10,11}$ However, we observed that the intervening portion of vein patch was regressed soon after the LDLT operation, thus its expansion effect to reduce the risk of anastomotic stenosis was less evident than expected.

We have continued to use an incision-and-patch venoplasty technique in LLS grafts without a superficial LHV branch to date, but recently a patch application was exempted if a superficial LHV branch was present, as shown in this case. Instead of performing a patch venoplasty at the LLS graft, we made the recipient hepatic vein orifice wall long and thick as far as we could. To achieve this preparation, we exposed the recipient LHV trunk long after peeling off the surrounding hepatic parenchyma and repaired the superficial LHV branch opening at the 3 o'clock direction. This preparation process makes the lateral half of the recipient LHV stump cover the exposed superficial LHV branch portion of a LLS graft as an overlying roof, therefore the use of a patch venoplasty at the graft side is deemed to no longer be necessary. To date, this technique has been applied to five infant recipients receiving a LLS graft, and none of them experienced any hepatic vein outflow obstruction.

The superficial branch of the LHV is usually too small to identify at the preoperative donor computed tomography or magnetic resonance imaging studies, thus the use of a unification venoplasty using this vein branch has to be decided after examination of the LLS graft at the back table. The clinical importance of this small vein branch is not evaluated yet, primarily because its drainage territory is negligibly small. Based on our experience, any small superficial branch of the LHV can be effectively used for unification venoplasty.

In conclusion, the unification venoplasty with the LHV trunk and its superficial vein branch makes the size of LLS outflow vein definitely larger than the original size, thus it can be a useful technical option to reduce the risk of hepatic vein outflow obstruction in pediatric LDLT using a LLS graft.

\section{ORCID}

Jung-Man Namgoong:

https://orcid.org/0000-0002-9237-7440

Shin Hwang: https://orcid.org/0000-0002-9045-2531

Gil-Chun Park: https://orcid.org/0000-0003-1631-3258

Hyunhee Kwon: https://orcid.org/0000-0001-6647-9155

Yong Jae Kwon: https://orcid.org/0000-0001-9490-1229

Sang Hoon Kim: https://orcid.org/0000-0002-8025-1816

\section{REFERENCES}

1. Karakayali H, Boyvat F, Coskun M, Isiklar I, Sözen H, Filik $\mathrm{L}$, et al. Venous complications after orthotopic liver transplantation. Transplant Proc 2006;38:604-606.

2. Hwang S, Lee SG, Choi ST, Moon DB, Ha TY, Lee YJ, et al. Hepatic vein anatomy of the medial segment for living donor liver transplantation using extended right lobe graft. Liver Transpl 2005;11:449-455.

3. Hwang S, Kim DY, Ahn CS, Moon DB, Kim KM, Park GC, et al. Computational simulation-based vessel interposition reconstruction technique for portal vein hypoplasia in pediatric liver transplantation. Transplant Proc 2013;45:255-258.

4. Galloux A, Pace E, Franchi-Abella S, Branchereau S, Gonzales E, Pariente D. Diagnosis, treatment and outcome of hepatic venous outflow obstruction in paediatric liver transplantation: 24-year experience at a single centre. Pediatr Radiol 2018;48: 667-679.

5. Katano T, Sanada Y, Hirata Y, Yamada N, Okada N, Onishi Y, et al. Endovascular stent placement for venous complications following pediatric liver transplantation: outcomes and indications. Pediatr Surg Int 2019;35:1185-1195.

6. Zhang ZY, Jin L, Chen G, Su TH, Zhu ZJ, Sun LY, et al. Balloon dilatation for treatment of hepatic venous outflow obstruction following pediatric liver transplantation. World $\mathrm{J}$ Gastroenterol 2017;23:8227-8234.

7. Lu KT, Cheng YF, Chen TY, Tsang LC, Ou HY, Yu CY, et al. Efficiency of transluminal angioplasty of hepatic venous outflow obstruction in pediatric liver transplantation. Transplant Proc 2018;50:2715-2717.

8. Yeh YT, Chen CY, Tseng HS, Wang HK, Tsai HL, Lin NC, et al. Enlarging vascular stents after pediatric liver transplantation. J Pediatr Surg 2017;52:1934-1939.

9. Veerankutty FH, Ali TU, Manoj KS, Venugopal B. Reconstruction of a rare variant of the left hepatic vein in a left lateral segment liver graft from a living donor: technical notes. J Indian Assoc Pediatr Surg 2016;21:41-43.

10. Imamura H, Makuuchi M, Sakamoto Y, Sugawara Y, Sano K, Nakayama A, et al. Anatomical keys and pitfalls in living donor liver transplantation. J Hepatobiliary Pancreat Surg 2000;7:380394.

11. Matsunami H, Makuuchi M, Kawasaki S, Hashikura Y, Ikegami T, Nakazawa $Y$, et al. Venous reconstruction using three recipient hepatic veins in living related liver transplantation. Transplantation 1995;59:917-919. 